2. Пашинян Г. А., Касумова С. Ю. Патоморфология и экспертная оценка повреждений головного мозга при черепно-мозговой травме. Москва, Ижевск: Экспертиза, 1994. - 134 с.

3. Саркисян Б. А., Бастуев Н. В., Паньков Н. В., Трубченков В. С. Сотрясение головного мозга. - Новосиб-к: Наука. Сибирск. изд. фирма РАН, 2000. -104 с.

4. Шевчук В. А. Судово-медична нейротравматологія: Навч. посібник .-К.: «МП Леся», 2003. - 80с.

\title{
INSTALLATION OF THE CRANIOCEREBRAL INJURY MECHANISM IN THE LIVING PERSONS
}

\author{
Shylan V. I., Shilova N. S., K. V. Shylan \\ Resume: The article presents the abilities of the installation of the craniocerebral injury mechanism of in- \\ ertial type in the living persons using Computed tomography,magnetic resonance tomography,multi-layer spiral CT. \\ The main features of the installation of the craniocerebral injury mechanism of inertial type, are location of shockproof injuries on the \\ frontal and temporal lobes with the transition to the basal plane with a bigger area of encephalon injury than on the area of the applica- \\ tion of force, injury asymmetry, localization character of the external injury.
}

Key words: the craniocerebral injury, the craniocerebral injury mechanism in the living persons

УДК 343.226:646-053.2/.5:17(07)

\section{СЛУЧАЙ ПРИМЕНЕНИЯ ПЫТОК НАД ЖЕРТВОЙ В СУДЕБНО-МЕДИЦИНСКОЙ ПРАКТИКЕ}

\author{
(С) Устинченко И. В.
}

\section{Луганское областное бюро судебно-медицинской экспертизы}

Говоря о насильственных действиях, пытках других жестоких, бесчеловечных или унижающих достоинство видов обращения и наказания в рамках Стамбульського протокола [1-3], наводим конкретный случай из практики судебно-медицинской экспертизы Луганского обласного бюро.

В один из вечеров февраля от дежурного районного отделения полиции поступило сообщение, о том, что в одном из домов в населенном пункте М. обнаружен труп гражданина С. с признаками насильственной смерти. Оперативно-следственная группа выехала на осмотр места происшествия. При наружном осмотре трупа было установлено: в лобной области справа и слева обнаружено по одному сино-фиолетового цвета кровоподтеку размером 6х3 см и 4х2 см. По нижней поверхности подбородка справа и в области верхней губы справа обнаружено по одному кровоподтеку аналогичного характера размером 2х2,7 см и 0,7x0,8 см (рис. 1). В области правой ушной раковины по верхнему краю основания обнаружена рана с относительно ровными не кровоподтечными краями, линейной формы проходящая сквозь все слои и хрящевую ткань длиной 2,1 см (рис. 2). На правой ушной раковине кнаружи от данной раны имеется две поверхностные раны длиной 0,7 и 0,9 см. В области левой ушной раковины у основания ее в верхней части имеется аналогичного характера рана с ровными не кровоподтечными краями длиной 3,9 см в глубине раны определяются поврежденные хрящи. Кожа вокруг раны с наложением подсохшей крови (рис. 3)

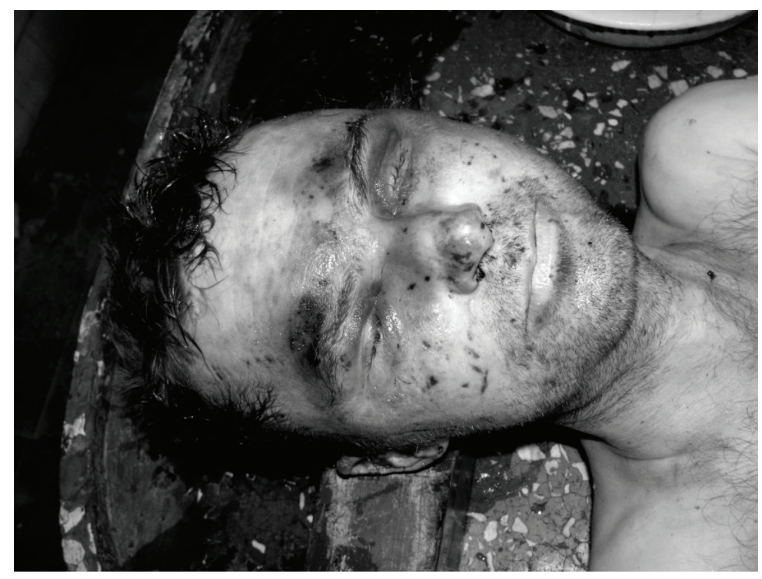

Рис. 1. Повреждения на лице 


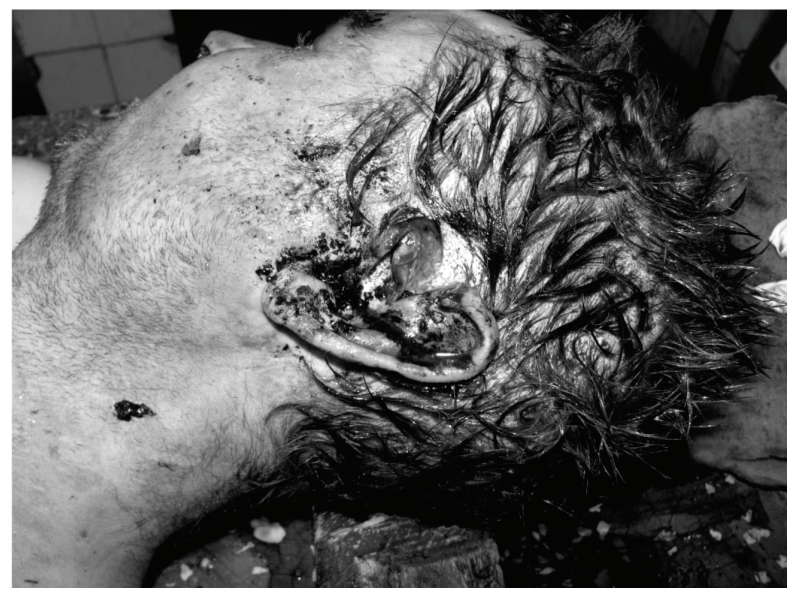

Рис. 2. Рана левой ушной раковины

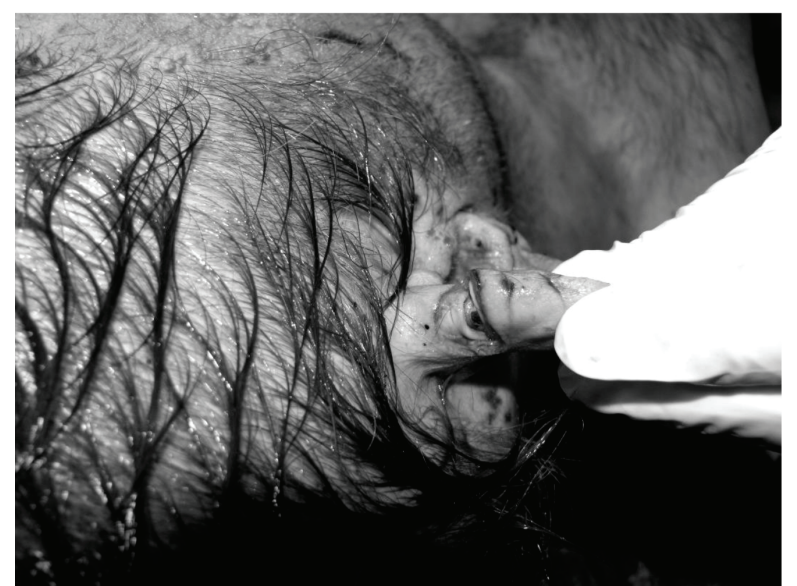

Рис. 3. Раны правой ушной раковины

В поясничной области справа и слева обнаружено 42 ссадины красно-коричневого цвета точечной, неопределенной и продолговатой формы размером от $0,1 \mathrm{x} 0,1$ см до 2,8х0,7 см. Края ссадин не ровные местами подрытые (рис. 4). По тыльной поверхности правой кисти обнаружено 20 аналогичного характера ссадины размером от $0,1 \times 0,1$ см до $1,5 \times 0,4$ см. В этой же области обнаружено три бледно синюшных кровоподтека размером $1 \times 1,5$ см; 2х1,8 см и 2х3 см (рис. 5). По тыльной поверхности левой кисти обнаружено 6 аналогичного характера ссадин размером от $0,1 \mathrm{x} 0,1$ см до $1,3 \mathrm{x} 0,3 \mathrm{~cm}$. По передней поверхности правой голени обнаружено две неопределенной формы ссадины размером $1,8 \mathrm{x} 0,6$ см и $1 \mathrm{x} 0,5$ см (рис. 6). По тыльной поверхности левой стопы обнаружено 37 ссадины аналогичного характера размером от $0,1 \times 0,1$ см до $3 \times 0,6$ см. У наружного мыщелка левой стопы обнаружена поверхностная рана с неровными кровоподтечными краями размером $2 \times 3$ см вокруг которой обнаружен бледно-синюшный кровоподтек размером $4 \times 5$ см.

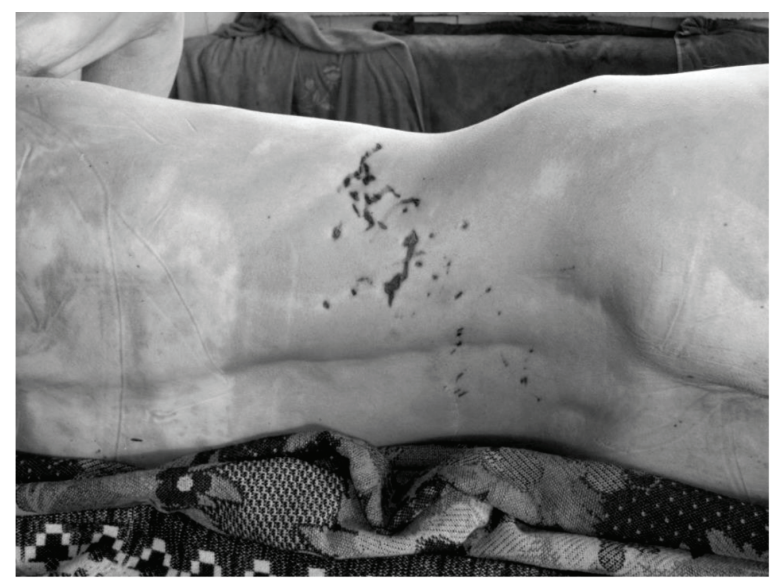

Рис. 4. Ссадины (электрометки поясничной области) 


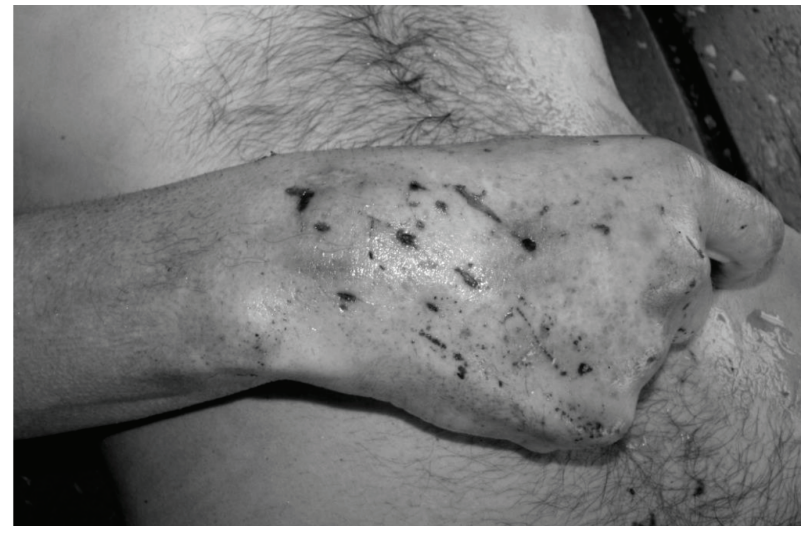

Рис. 5. Ссадины (электрометки правой кисти)

По тыльной поверхности правой стопы и в верхней части правой голени обнаружено 18 аналогичного характера ссадины размером от $01, \mathrm{x} 0,1$ см од 2,1х0,4 см (рис. 7). В области лица обнаружено 19 аналогичного характера ссадин размером от $0,1 \mathrm{x} 0,1$ см до $0,5 \mathrm{x} 0,2$ см. Вокруг правого и левого глаза обнаружено по одному аналогичного характера кровоподтеку размером $4 \times 5$ и 4.3 см. В области переносицы и спинки носа справа имеется по одному аналогичного характера кровоподтеку размером 1 х2 см м 1,5х1,9 см.

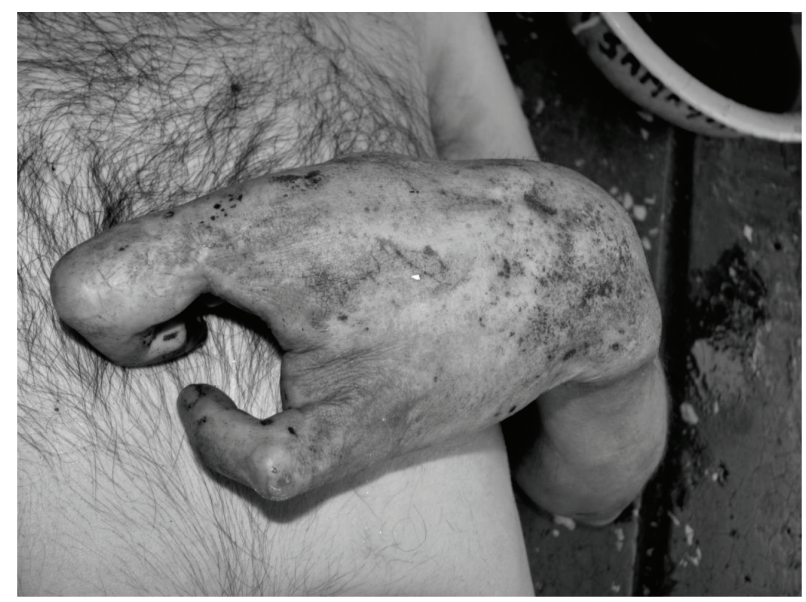

Рис. 6. Ссадины (электрометки левой кисти)

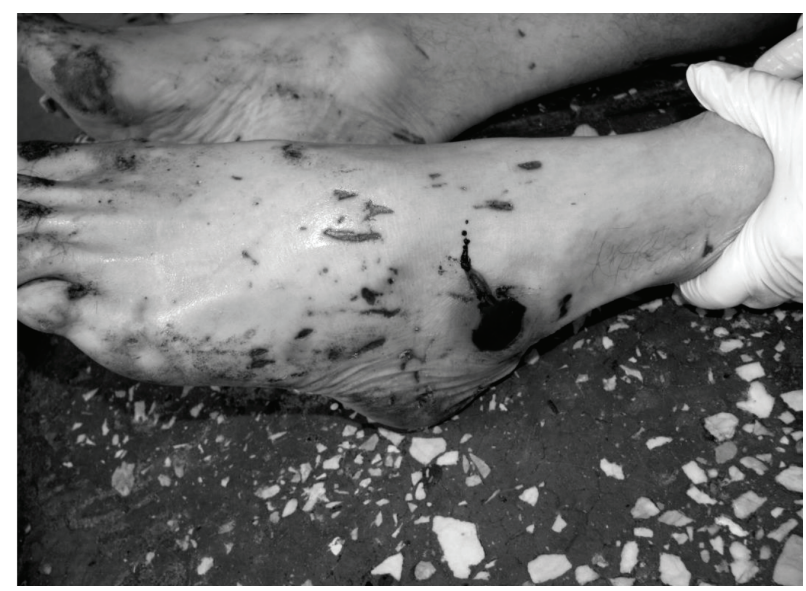

Рис. 7. Ссадины (электрометки стоп)

Со слов подозреваемых (которых было двое) было известно, что они наносили удары руками и ногами в область головы и грудной клетки, затем один из подозреваемых взял маникюрные ножницы и пытался отрезать ушные раковины. Образование данных телесных повреждений не вызывало никаких сомнений. Одно насторожило, наличие большого количества ссадин в области туловища, конечностей и лица. На вопрос о механизме их образования, подозреваемые, несколько занервничали и не дали убедительного ответа о механизме образования. 
Учитывая, что осмотр трупа проводился в ночное время суток, при плохом освещении, было решено, что более детальный механизм их образования будет установлен при экспертизе трупа в морге. В результате проведенной экспертизы, детального осмотра ссадин, под увеличительным стеклом, осмотра фотографий повреждений под большими увеличением я пришёл к выводу, что данные ссадины являются электрометками (что в последствии было подтверждено гистологическим и медико-криминалистическим исследованием).

При экспертизе трупа была установлена причина смерти гр. С. наступила от закрытой черепно-мозговой травмы с кровоизлияниями под оболочки и вещество головного мозга.

При экспертизе трупа С. были обнаружены следующие повреждения: ссадины и кровоподтеки лица; кровоизлияния в мягкие покровы головы со стороны их внутренней поверхности; кровоизлияние под мягкую мозговую оболочку правого и левого полушария головного мозга, в продолговатый мозг, стволовую часть мозга и желудочки мозга; раны с ровными не кровоподтечными краями правой и левой ушной раковины с повреждением хрящевой части; закрытая травма органов грудной клетки переломы 8,9 ребер справа с кровоизлиянием по реберную плевру и в межреберные мышцы; ушиб правого легкого; кровоизлияния в толщу поджелудочной железы множественные ссадины поясничной области тыльной поверхности правой и левой кисти, а также тыльной поверхности стоп. Описанные выше повреждения прижизненные, образовались в небольшой промежуток времени, не за долго, до наступления смерти. Повреждения в виде закрытой черепно-мозговой травмы с кровоизлияниями под оболочки и вещество головного мозга образовались от действия тупого предмета, предметов по степени тяжести имеют признаки тяжких телесных повреждений (по признаку опасности для жизни). Повреждения в виде переломов ребер, кровоизлияния на поверхности легких и в толщу поджелудочной железы образовались от действия тупого предмета, предметов, имеют признаки повреждений средней степени тяжести (по признаку длительного расстройства здоровья). Обнаруженные повреждения в виде ран правой и левой ушной раковины образовались от действия какого то предмета обладающего режущими свойствами, по степени тяжести имеют признаки легких телесных повреждений, как повлекшие за собой кратковременное расстройство здоровья. Повреждения в виде ссадин лица, поясничной области, тыльной поверхности правой и левой кисти, а также тыльной поверхности стоп, учитывая результаты медико-криминалистического и гистологического исследования, являются электрометками и образовались в результате многократного (как минимум 142 кратного воздействия) воздействия предмета с ограниченной контактирующей поверхностью который был подсоединен к электричеству. По степени тяжести имеют признаки легких телесных повреждений.

При проведении следственного эксперимента с подозреваемыми было установлено, что после причинения телесных повреждений обнаруженных в области головы и грудной клетки, они пытаясь выбить долг с гр. С., взяли два провода, один из которых был подсоединен к розетки и закреплен на 1 пальце правой стопы потерпевшего, другой провод был подсоединён к другому выходу розетки, а свободным концом производились воздействия на тело потерпевшего (задняя поверхность туловища, лицо, конечности), которая продолжалась в течении 40 - 45 минут. После причинения этих воздействий С. оставался живым еще 30 - 40 минут, находился без сознания, после наступила смерть.

ВЫВОД. В последствии многократность воздействий на тело гр. С., правоохранительными органами было расценено как применение пыток и мучений над жертвой.

\section{Литература}

1. Стамбульский протокол. Руководство по эффективному расследованию и документированию пыток и других жестоких, бесчеловечных или унижающих достоинство видов обращения и наказания, 1999. - 113 с.

2. Визначення понять i систематизація насильницьких дій шляхом нанесення побоїв, заподіяння мордувань $\mathrm{i}$ катувань / В.Д.Мішалов, М. М. Тагаєв, В. В. Хижняк, А. О. Моргун // Судово-медична експертиза. - 2015. №1. - С. 8-19.

3. Кримінально-процесуальний кодекс України. Вид-во «Центр учбової літератури». - Київ, 2012. - 290 с. 